\title{
EL CONCEPTO DE CRÉDITO EN EL DERECHO CHILENO*
}

\author{
Alejandro GuZMÁN BRITO**
}

RESUMEN: El trabajo se propone indagar sobre el concepto de "crédito”, bajo una acepción distinta a la que se desprende del artículo 578 CC., como sinónimo de "derecho personal". Se parte de la noción de "operación de crédito", que, no bien limitada al dinero en la Ley $\mathrm{N}^{\circ}$ 18.010, admite ser extendida a la dación en propiedad de toda clase de cosas que con posterioridad deben ser restituidas por quien las recibe y no confundirla con la figura del mutuo. Se examinan algunos casos típicos de acreditaciones como el pago de lo no debido, los negocios irregulares como el depósito de esa clase, las que los romanos denominaban dare ob rem, la donación por causa de muerte y la dación de arras.

PALABRAS CLAVE: Crédito-derecho personal-operación de créditomutuo-dare ob rem-donación por causa de muerte-arras

\section{THE CONCEPT OF CREDIT IN CHILEAN LAW}

ABSTRACT: This paper investigates the concept of "credit" in a different sense to the idea that emanates from the article 578 CC., as a synonym for "personal right". It starts from the notion of "credit operation" that, although limited to money in Law $\mathrm{N}^{\circ} 18.010$, admits to be extended to all transference of property of all kinds of things that later must be returned by the receiver and not confused with the figure of the loan. Some typical cases of credits as the undue payment are examined:

Este artículo constituye la ponencia que su autor presentó en el VIII Seminario de Derecho Civil: "El derecho privado ante los desafíos contemporáneos", organizado por Facultad de Ciencias Jurídicas y la Escuela de Derecho de la Universidad Católica del Norte, en Antofagasta los días 27 a 29 de agosto de 2014. Él hace parte de una investigación que al mismo tiempo concierne al proyecto patrocinado por el Fondo de Investigación Científica y Tecnológica de Chile, bajo el número 1130646, cuyo título es: "Los actos irregulares o anómalos en el Derecho chileno"; y al proyecto Anillo de Investigación Asociativa patrocinado por la Comisión de Investigación Científica y Tecnológica bajo el código SOC 1111: "Estudios dogmáticos de Derecho patrimonial privado".

Fecha de recepción: 23 de septiembre de 2014.

Fecha de aceptación: 2 de octubre de 2014.

** Catedrático de Derecho Romano de la Pontficia Universidad Católica de Valparaíso (Chile). Correo electrónico: aguzman@ucv.cl. 
the irregular deposit, the acts which the Romans called dare ob rem, the donation by cause of death and the delivery of arras.

KEY WORDS: Credit-personal right-credit operation-loan-dare $o b$ rem-donation by cause of death-delivery of arras.

1) De acuerdo con el artículo 578 CC., el término “crédito" es si-

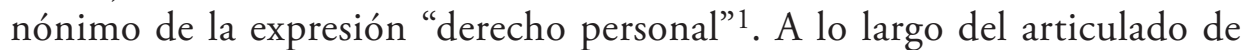
ese cuerpo legal, el vocablo crédito prácticamente no ofrece otro sentido que no sea el mentado por la disposición $\operatorname{citada}^{2}$, que, en síntesis, alude a las obligaciones de cualquier clase miradas desde el punto de vista del acreedor. En el lenguaje comercial y en el común, la palabra "crédito" está vinculada con el "crédito mutuario" por medio de bancos y otras instituciones financieras, el "crédito prendario" ejercido por la Caja de Crédito Popular, que no es otra cosa que un mutuo garantizado con prenda de muebles valiosos, generalmente joyas y otros objetos preciosos, la "compraventa a crédito" en el comercio mayoritario y detallista, los títulos de crédito y con las "tarjetas de crédito".

La Ley $\mathrm{N}^{\circ} 18.010$ (DO. de 27 de junio de 1981), que vino a reemplazar a un Decreto-ley $\mathrm{N}^{\circ} 455$ (D.O. de 25 de mayo de 1974), trata de las que denomina "operaciones de crédito de dinero". Según el inciso $1^{\circ}$ de su artículo 1, por tales se entienden "aquéllas por las cuales una de las partes entrega o se obliga a entregar una cantidad de dinero y la otra a pagarla en un momento distinto de aquel en que se celebra la convención". El inciso $2^{\circ}$ también incluye dentro del concepto al descuento de documentos representativos de dinero, sea que la operación lleve o no envuelta la responsabilidad del cedente. Pero el inciso $4^{\circ}$, en cambio, excluye de la aplicación de la ley "las operaciones de crédito de dinero correspondientes a contratos aleatorios, arbitrajes de monedas a futuro, préstamo maritimo o avio minero". Como se ve, la norma no dice que estas últimas actuaciones no sean "operaciones de crédito de dinero", pues, por el contrario, las denomina expresamente así; solo, repetimos, las excluye del ámbito de vigencia de la ley ${ }^{3}$.

2) Interesa recalcar que las operaciones de crédito en el sentido de la Ley $\mathrm{N}^{\circ} 18.010$ son solo las de dinero. Pero los créditos en el sentido

\footnotetext{
$1 \quad$ Artículo 578 CC.: "Derechos personales o créditos son los que solo pueden reclamarse de ciertas personas, que, por un hecho suyo o la sola disposición de la ley, han contraido las obligaciones correlativas; como el que tiene el prestamista contra su deudor por el dinero prestado, o el hijo contra el padre por alimentos. De estos derechos nacen las acciones personales".

2 Si dejamos a un lado el artículo 2331 CC. En donde se habla de las "imputaciones injuriosas contra el honor o el crédito de una persona”, pues ahí nuestro término está tomado en su sentido de "buena reputación o fama".

3 En realidad del título $1^{\circ}$ de la ley ("No se aplicarán las disposiciones de este título a [...]"..
} 
del artículo 578 CC. pueden ser de dinero o de cualquier otra cosa que no lo sea y desde luego de servicios y abstenciones. Sin embargo, tal cual concibe su objeto la Ley $\mathrm{N}^{\circ} 18.010$, hay un elemento en el concepto de "operación de crédito de dinero" que vale la pena rescatar. Ella exige que una cantidad de dinero sea entregada o prometida entregar por una parte a otra, y que esta última se obligue a pagarla en un momento posterior. Según esto, los tipos específicos de "operaciones de crédito de dinero", según la ley, son dos y consisten en: $i$ ) entregar actualmente una cantidad de dinero con la obligación asumida de pagarla después; ii) prometer actualmente una cantidad de dinero con la obligación asumida de pagarla después ${ }^{4}$. El primer tipo constituye un acto real y obligacionalmente unilateral, porque solo crea una obligación para el que recibió la cantidad, consistente en la de restituirla posteriormente, como, acaece en el mutuo de dinero. El segundo, en cambio, constituye un acto consensual bilateralmente obligacional, pues para una parte crea la obligación de dar la cantidad prometida y para la otra, no la de recibirla, sino la de restituirla en un momento posterior. La ley no añade que esta segunda obligación además quede sometida a la condición positiva suspensiva de que la cantidad sea entrega y recibida; pero que sea así no es posible siquiera discutirlo, porque no resulta aceptable que alguien se obligue pura y simplemente a restituir una cosa que no ha recibido.

Tal es cuanto acontece, por ejemplo, en el "contrato de línea de crédito", merced al cual un banco se obliga a pagar los cheques girados por un cuentacorrentista suyo sin el respaldo de fondos en la cuenta propia, hasta cierto monto total acordado. El cuentacorrentista debe restituir las cantidades sobregiradas y sus intereses, en determinados tiempos posteriores. La obligación de restituir y de pagar intereses no nace, por cierto, sino con el pago del cheque sobregirado. Pero el contrato es legalmente consensual y no real; así que, con su celebración, el banco queda obligado a cubrir los cheques sobregirados, y debe responder del perjuicio causado por la omisión injustificada de cobertura y del eventual protesto por falta de fondos. En el fondo, lo que el banco debe hacer es atender a la petición de crédito por parte del cliente, petición que se manifiesta con la presentación del cheque sobregirado por su beneficiario (que por supues-

\footnotetext{
La dualidad "entregar/obligarse a entregar" ya estaba presente en el antecedente del inciso $1^{\circ}$ del artículo 1 de la Ley $\mathrm{N}^{\circ} 18.010$ que fue el inciso $1^{\circ}$ del artículo 1 del Decreto-ley $\mathrm{N}^{\circ}$ 455: Fija normas respecto de las operaciones de crédito de dinero (D.O. de 25 de mayo de 1974); que decía: "Es operación de crédito de dinero todo acto o contrato en virtud del cual una persona entrega o se obliga a entregar una cantidad de dinero a otra, quien se obliga a restituir el valor recibido, numérico o reajustado, con o sin intereses, sea bajo la forma de préstamo o mutuo, depósito, apertura de crédito, avances o préstamos contra suscripción de instrumentos o en cualquiera otra forma, incluyéndose especialmente el descuento. Para estos efectos, se entiende por dinero la moneda nacional o extranjera y los instrumentos negociables representativos de obligaciones en moneda nacional o extranjera".
} 
to puede ser el mismo cuentacorrentista) en caja, o por otro banco en el momento de la compensación bancaria, si el cheque fue depositado en él. El cliente se asegura, de esta manera, tener fondos para cuando los necesite. En este contrato, pues, una parte se obliga a entregar dinero y la otra a pagarlo desde que lo reciba.

El carácter condicional de la obligación de restituir cuando el contrato es consensual constituye solo la primera las complicaciones que asaltan a la creación de un tal contrato que obligue bilateralmente a dar y a restituir dinero, destinado a sustituir al real que se perfecciona por la dación y que obliga unilateralmente a solo restituir lo recibido. Pero no nos ocuparemos de esta materia aquí ${ }^{5}$.

3) Por lo mismo dejaremos a un lado momentáneamente el tipo consistente en prometer dar una parte y obligarse a restituir lo recibido (y cuando lo sea) la otra, para concentrarnos en el tipo real consistente en "entregar y obligarse a restituir". Es tal estructura la que queremos rescatar del concepto de "operación de crédito de dinero" que ofrece la Ley $\mathrm{N}^{\circ}$ 18.010, porque ella contiene el concepto propio de crédito que deseamos exponer en este trabajo.

La figura que, en efecto, nos interesa describir aquí consiste en un traspaso de cosas en propiedad de uno a otro, llamado "dación", que en principio obliga a quien recibió a restituirlas con posteriortidad al que las dio, aunque no necesariamente porque es posible el caso de poder retenerlas el que las recibió ${ }^{\text {. }}$

Debo destacar de inmediato algunos caracteres:

a) Por lo que atañe al objeto de la operación, no se trata solo de la dación de dinero, y aquel puede consistir en cualquier cosa corporal o incorporal, mueble o inmueble, fungible o infungible, consumible o inconsumibles. Se comprenderá, por consiguiente, que las operaciones de crédito de dinero son únicamente una especie de las operaciones, actuaciones o figuras crediticias.

b) Se excluyen todos los traspasos de cosas por entrega en mera tenencia, como el depósito y el secuestro, el comodato, la prenda, el usufructo, el uso y la habitación o el transporte de cosas. La razón deriva de la definición estipulativa del crédito, que debe consistir en una dación, vale decir,

5 Lo hemos hecho en Guzmán Brito, Alejandro (2007 a), "La consensualización de los contratos reales". Revista de Derecho de la Pontificia Universidad Católica de Valparaíso, 29 No 2, pp. 35-60 [= (2009): en Avendaño Valdez, Jorge y otros (editores): Homenaje a Fernando de Trazegnies Granda. Lima: Fondo Editorial de la Pontificia Universidad Católica del Perú, t. II, pp. 131-156].

6 Este concepto es diferente de aquel que describe Simonetro, Ernesto (1953/1958), Los contratos de crédito, traducción al castellano. Madrid: Bosch, limitado a los fungibles. Por lo demás, esta obra es fundamental para el estudio del crédito. 
en un traslado del dominio y de la posesión de la cosa de que se trate; lo que no acontece en los actos que se mencionó precedentemente.

c) El crédito no se confunde con el mutuo o préstamo de fungibles ${ }^{7}$, como ya debió de quedar claro con el enunciado de las cosas que pueden ser su objeto, en muchas de las cuales un mutuo no puede recaer, y basta mencionar como ejemplos los inmuebles.

d) La dación o traspaso o transferencia de dominio, que es la base de todo crédito, tiene lugar normalmente por la tradición de la cosa de que se trate, hecha de conformidad con alguno de los tipos de tal aceptados por la ley. Si, por alguna causa, la tradición no surtió el efecto dominical que le es propio, porque, por ejemplo, se dio una cosa ajena, no hay dación; pero sobreviniendo la prescripción adquisitiva ordinaria o extraordinaria, entonces tiene lugar la dación, porque entonces es que se produce la adquisición del dominio.

e) El justo título traslaticio del dominio que debe operar en la tradición de que hablamos es el crédito mismo ${ }^{8}$; y decimos que se trata de una traditio credendi causa o pro creditore.

f) También puede tener lugar la dación mediante un legado de efectos reales, por el cual se atribuya el dominio de la cosa de que se trate al legatario, lo cual tiene lugar de acuerdo con las reglas generales que rigen en esta llamada "sucesión a título singular", que principalmente incluyen muerte del testador y la aceptación del legado?.

g) Por consiguiente, la idea de crédito supone la adquisición del dominio de una cosa, pero también la de empezar a estar obligado a su restitución: la cosa es de alguien, quien, sin embargo, la debe. Entre ambas situaciones no hay, por cierto, ninguna contradicción o incompatibilidad, como se demuestra, por ejemplo, en el mutuo, el más típico caso de crédito, en que el mutuario adquiere el dominio de los fungibles que recibió en préstamos (artículo 2197 CC: el mutuo se perfecciona por la tradición "y la tradición transfiere el dominio") y desde luego debe restituir otro tanto del mismo género y calidad al mutuante (artículos 2196, 2198, 2200 CC.).

7 En Dig. 12,1,2,3 (Paul., 27 ed.) se encuentra una precisa diferenciación entre el crédito y el mutuo: "Creditum ergo a mutuo differt qua genus a specie: nam creditum consistit extra eas res, quae pondere numero mensura continentur sic, ut, si eandem rem recepturi sumus, creditum est. [...]" ("Por consiguiente, el crédito difiere del mutuo en lo que el género de la especie: porque el crédito tiene consistencia [incluso] fuera de las cosas que se contienen en el peso, número o medida, así como [también] hay crédito si hemos de recibir la misma cosa").

8 Sobre esta materia, véase: GuZmán Brito, Alejandro (2007), "El justo título traslaticio de dominio de la tradición en el pago y en las operaciones crediticias, en Corral Talciani, Hernán y Rodríguez Pinto, María Sara (coordinadores), Estudios de Derecho Civil II: Jornadas Nacionales de Derecho Civil. Santiago: LexisNexis, espec cap. III: "El título traslaticio de dominio en la operaciones crediticias", pp. 711-719.

9 Sobre los legados de efecto real, vale decir, que confieren la propiedad de una cosa corporal o la titularidad de un derecho real, véase: Guzmán Brito, Alejandro (2006), "La tipología de los legados en el Derecho civil chileno". Revista de Derecho de la Pontificia Universidad Católica de Valparaíso, vol. 27, No 2, cap. II: "Legado de efecto real", pp. 57-62. 
4) Para captar mejor el diseño concreto de la figura en estudio recurriremos al ejemplo del pago de lo no debido.

a) La correcta comprensión de este ejemplo que, como es sabido, el Código Civil considera un caso específico del esquema general del cuasicontrato, supone aproximarlo al tipo de pago que el Código Civil describe como aquel "en que se debe transferir la propiedad" (artículo 1575 inciso $1^{\circ}$ CC.) y se diferencia, por ende, del que contiene la prestación de hacer o de no hacer y la de entregar cosas en mera tenencia, que en realidad también consiste en hacer ${ }^{10}$.

El pago de lo debido es, pues, un pago; o, lo que es lo mismo decir, un pago puede ser debido o no debido. En rigor el pago del que tratamos es la dación de una cosa en dominio dirigida a extinguir la obligación de dar esa cosa. Si la obligación existe, la dación alcanzó su objetivo y el que recibió la cosa en propiedad puede retenerla; pero si la obligación no existe, la dación no consiguió su fin, y el que recibió la cosa no pueda retenerla, sino que debe restituirla. Tales efectos aparecen descritos por los artículos 1568 CC.: "El pago efectivo es la prestación de lo que se debe"; y 2295 inciso $1^{\circ}$ CC.: "Si el que por error ha hecho un pago, prueba que no lo debia tiene derecho para repetir lo pagado". Por consiguiente, si alguien hizo un pago y no prueba que fue indebido, no puede repetirlo, porque se entiende haberse tratado de la prestación de lo debido.

b) Cuando el pago fue indebido, decimos que la cosa quedó acreditada en manos del que recibió la cosa. Si esta consistió en una cantidad de dinero o de otros fungibles, la situación en que ella queda en manos del que la recibió es la misma en que hubiera quedado si la cantidad le hubiese sido dada en mutuo; y a través de esta comparación se puede percibir muy bien el carácter de acreditada que atribuimos a la cosa pagada indebidamente ${ }^{11}$.

De paso recordemos que el título traslaticio que opera en la tradición en que consiste el pago indebido es pro soluto, porque se trata de un pago; pero que se le ańade el título pro creditore, por ser haber sido indebido; lo cual es perfectamente posible merced a la regla del artículo $701 \mathrm{CC}$. en orden a poder poseerse una cosa por varios títulos ${ }^{12}$, lo cual implica podérsela recibir de la misma manera.

La situación no varía si lo pagado es una especie no fungible, como cuando, por ejemplo, se haya prometido donandi causa cierta obra de

\footnotetext{
10 El pago indebido de cosas que no implica el tránsito del dominio sobre lo pagado (como si se restituye otra cosa por la verdaderamente depositada, dada en comodato o pignorada) se rige por otras reglas y no nos interesan aquí

11 Cfr. la definición de mutuo en el artículo 2196 CC. como contrato en que una de las partes entrega a la otra cierta cantidad de cosas fungibles "con cargo de restituir otras tantas del mismo género y calidad"; con la definición de cierto pago indebido contenida en el artículo 2300 CC., como haber alguien recibido dinero o cosa fungible que no se le debía, lo cual lo deja "obligado a la restitución de otro tanto del mismo género y calidad".

12 Guzmán Brito (2007) cap. II, 7 a), pp. 707-708; y cap. III, 8, p. 718.
} 
arte, y el donante deudor pagara por error con otra. Entretanto la cosa inicialmente pagada permanece en el donatario donandi y credendi causa: es suya, pero la debe restituir al donante.

5) Después del mutuo, el pago de lo indebido es un señalado caso de crédito, pero ni el uno ni el otro son los únicos.

a) Desde luego se presentan todos los casos de negocios irregulares. Siguiendo el modelo iniciado por comentaristas del siglo XIV, llamamos irregulares a ciertos negocios que normalmente deben recaer sobre infungibles e inconsumibles, pero que las partes, deliberadamente y sin error, celebran sobre fungibles o consumibles. La lista es taxativa; se encuentran en el caso los siguientes actos irregulares: la constitución de usufructo (artículo 789 CC.), el depósito (artículo 2221 CC.), la prenda y el arrendamiento para la confección de una obra material; discutiblemente el comodato cuando la cosa prestada se entrega evaluada.

La importancia de la teoría del crédito para los actos irregulares radica en que al adoptar estos la respectiva forma irregular dan lugar precisamente a una relación crediticia. Que no necesitemos sostener que lo acaecido entonces sea que el acto haya transitado a un mutuo, es el margen explicativo que nos proporciona la teoría del crédito, porque si decimos que el depósito irregular, por ejemplo, es un crédito, pero no un mutuo, eso permite superar muchas discusiones y problemas que surgen cuando no se toma en cuenta el concepto abstracto de crédito.

Observemos el régimen que aparece en dos importantes códigos uno del siglo XIX y otro del XX.

b) El \$ 959 del Código Civil austriaco (Allgemenes Bürgerliches Gesetzbuch) de 1811 dispone:

"Wird dem Verwahrer auf sein Verlangen, oder durch freiwilliges Anerbieten des Hinterlegers der Gebrauch gestattet; so hört im ersten Falle der Vertrag gleich nach der Verwilligung; im zweiten aber von dem Augenblicke, da das Anerbieten angenommen, oder von der hinterlegten Sache wirklich Gebrauch gemacht worden ist, auf, ein Verwahrungsvertrag zu sein; er wird bei verbrauchbaren Sachen in einen Darlehens-, bei unverbrauchbaren in einen Leihvertrag umgeändert, und es treten die damit verbundenen Rechte und Pflichten ein”.
"Si queda permitido el uso [de la cosa] al depositario, sea a petición suya, sea por libre ofrecimiento del depositante, el contrato cesa de ser un depósito, desde la convención [misma] en el primer caso, pero desde el momento en que la petición es aceptada o desde que realmente se ha hecho uso de la cosa depositada en el segundo; tratándose de cosas fungibles, aquél se transforma en un mutuo; y de cosas no fungibles, en un comodato; y [entonces] tienen lugar los derechos y obligaciones correspondientes a uno u otro". 
Para este cuerpo legal, pues, el depósito que recae sobre fungibles respecto de los cuales se conceda la facultad de usarlos al depositario, se convierte sin más en un mutuo, y entonces tienen lugar los derechos y obligaciones propios de este contrato.

Veamos ahora el artículo 1782 del Codice Civile de 1942:

"Deposito irregolare./ Se il deposito ha per oggetto una quantità di danaro o di altre cose fungibili, con facoltà per il depositario di servirsene, questi ne acquista la proprietà ed è tenuto a restituirne altrettante della stessa specie e qualità./ In tal caso si osservano, in quanto applicabili, le norme relative al mutuo".
"Depósito irregular. Si el depósito tiene por objeto una cantidad de dinero o de otras cosas fungibles, con la facultad para el depositario de servirse de ellas, éste adquiere la propiedad y es obligado a restituir otra tanta de la misma especie y calidad. En tal caso se observan, en cuanto aplicables, las normas relativas al mutuo".

La norma es más completa y descriptiva que la austriaca; pero la conclusión viene a ser la misma: al depósito de dinero u otros fungibles se aplican las normas del mutuo. Hay ciertamente un matiz de diferencia: para el código austriaco tal es así porque el depósito se transforma en mutuo. El italiano no da sus razones ni, en especial, no dice que el depósito transita a mutuo; además, tiene la precaución de advertir que deben observarse a las normas del mutuo "en cuanto aplicables".

c) Examinemos ahora el contenido del artículo 2221 CCCh.: "En el depósito de dinero, si no es en arca cerrada cuya llave tiene el depositante, o con otras precauciones que hagan imposible tomarlo sin fractura, se presumirá que se permite emplearlo, y el depositario será obligado a restituir otro tanto en la misma moneda". Podemos preguntarnos si la figura tratada en esta disposición sea un mutuo o un depósito. Se observará que, a diferencia de los códigos antes presentados, el chileno no se pronuncia al respecto. Ahora bien, que no se trata del depósito propiamente dicho, como lo llama el Código, eso es algo seguro porque, de acuerdo con los artículos 2211 y 2215 CC., la cosa corporal depositada ha de ser restituida "en especie" por el depositario al depositante. Pero eso que mandan tales disposiciones solo puede ser cumplido si la cosa depositada ya era una especie (o cuerpo cierto) ella misma; y si es así, no pudo tratarse de fungibles ${ }^{13}$.

13 Cierto es que las nociones de cosa fungible y no fungible no son las mismas que las de cosas genéricas y específicas; como, empero, sí es cierto que las cosas fungibles se designan genéricamente y específicamente las infungibles, en la práctica resultan coincidentes. Es por tal razón que, en el lenguaje del código, el término "especie" (o cuerpo cierto) mienta una cosa infungible (desde luego designada específicamente). 
Por lo demás, el artículo 2228 CC. ordena: "El depositario es obligado a la restitución de la misma cosa o cosas individuales que se le han confiado en depósito [...]". La expresión "cosa o cosas individuales" está por "especie o especies" en la norma. Ahora bien, el artículo $2221 \mathrm{CCCh}$. dice que el depositario de dinero será obligado a restituir no el mismo dinero recibido sino "otro tanto en la misma moneda". En consecuencia, la figura de esa disposición no puede ser un depósito propiamente dicho. Ella recuerda bien al tipo descrito bajo el nombre de "mutuo" en el artículo 2196 CC. como un contrato en que una de las partes entrega a la otra cierta cantidad de cosas fungibles con cargo de restituir otras tantas del mismo género y calidad; ya que en el caso del artículo 2221 CCCh. en examen, precisamente se trata de una cantidad de dinero recibido cuyo receptor ha de restituir otro tanto en la misma moneda. Pero entonces, ¿por qué el Código no trató el caso en el título $21^{\circ}$ : "Del mutuo o préstamo de consumo" del libro IV CC., sino en el $\$ 1$ : "Del depósito propiamente dicho" del título 32: "Del depósito" del libro IV CC.?

d) $\mathrm{Mi}$ respuesta es que el artículo $2221 \mathrm{CCCh}$. describe una figura crediticia, no un mutuo, que las partes, empero, quieren tratar de acuerdo con las reglas del depósito. El carácter crediticio viene de la estructura ya examinada consistente en la dación de una cosa -dinero en la especie, pero que la analogía permite extenderse a los demás fungibles ${ }^{14}$ - , la cual, pese a hacerse del que la recibió debe restituirla. Pero como esta relación crediticia no es mutuaria, no se ve afectada por el artículo 2198 CC., que dice que en el mutuo de fungibles que no sean dinero se debe restituir igual cantidad de cosas del mismo género y calidad, sea que el precio de ellas haya bajado o subido en el intervalo; pero que si esa restitución no fuere posible o no lo exigiere el acreedor, podrá el mutuario pagar lo que los fungibles valgan en el tiempo y lugar en que ha debido hacerse el pago; así que en el depósito de fungibles no cabe esta sustitución.

Tampoco es aplicable el artículo 2200 CC.: si no se hubiere fijado término para el pago de los fungibles dados en mutuo, no habrá derecho de exigirlos dentro de los diez días subsiguientes a la entrega; y, en cam-

14 La cual se ve apoyada por el artículo 2228 CC.: "El depositario es obligado a la restitución de la misma cosa o cosas individuales que se le han confiado en depósito, aunque consistan en dinero o cosas fungibles; salvo el caso del artículo 2221". La norma hace referencia a "cosas que consistan en dinero o cosas fungibles", que si fueron depositadas deben ser devueltas las mismas; pero impone la excepción del artículo 2221; lo cual significa que, cuando se depositó dinero o cosas fungibles no en arca cerrada cuya llave tenga el depositante, ni con otras precauciones que hagan imposible tomar ese dinero o cosas fungibles sin fractura del arca, entonces el depositario quedará en los términos de la última frase del citado artículo. Ahora bien, todo este discurre sobre la base de solo el depósito "de dinero"; mientras que el artículo 2228 lo hace sobre la base del depósito "de dinero o de cosas fungibles"; y entonces una de dos: o el artículo 2221 es inaplicable a la hipótesis del artículo 2228 pese a la remisión expresa de este a aquel en orden a aplicarlo; o es aplicable; y en este último caso, el artículo 2221 hay que entenderlo también referido a las cosas fungibles aunque no sean dinero. 
bio rige la regla del depósito dada en los artículos 2215 y 2226 CC. en orden a que la restitución de lo depositado es a voluntad del depositante.

Del mismo modo no es aplicable la regla del artículo 2203 CC. que hace responsable al mutuante por los perjuicios que experimente el mutuario por la mala calidad o los vicios ocultos de la cosa prestada, en los términos expresados por el artículo 2192.

De igual manera no resulta ajustable la regla del artículo 2204 merced a la cual el mutuario puede pagar la suma prestada antes del término estipulado, salvo que se haya pactado intereses, porque en el depósito rige el artículo 2226 inciso $2^{\circ}$, el cual prescribe que si se ha fijado un tiempo para la restitución, la cláusula solo obliga al depositario y en virtud de ella no podrá devolver la cosa depositada antes del tiempo establecido, salvo que las leyes lo autoricen expresamente, como en el caso del artículo 2216 inciso $2^{\circ 15}$.

e) El Código chileno no trata expresamente como un mutuo al depósito de dinero u otros fungibles, a diferencia de otros cuerpos legales; ni tácitamente lo reconduce a él, pese a consistir por su naturaleza en una figura crediticia, porque el mutuo no se confunde con el crédito. Lo único que podemos decir es que el depósito de dinero u otros fungibles -llamado irregular en la tradición romanística- es una figura crediticia que se rige por algunas reglas del depósito; y entre las principales: $i$ ) que la restitución es a voluntad del depositante (artículos 2215 y 2226 inciso $1^{\circ} \mathrm{CC}$.); ii) que el error en la identidad de los contratantes o en la sustancia, calidad o cantidad de la cosa depositada no invalida el contrato (artículo 2216 inciso 1$]^{\circ}$ CC.); iii) cuando se omitió extender el contrato por escrito debiendo haberlo hecho según las reglas generales, se debe estar a la palabra del depositario en cuanto al hecho del depósito, a la cosa depositada y al hecho de la restitución (artículo 2217 CC.); iv) la incapacidad de las partes no tiene el efecto normal de la incapacidad que se ve atenuada (artículo 2218 CC.); etcétera.

La fórmula que hemos planteado según la cual el depósito irregular no es un mutuo ni un depósito sino un crédito, que se rige por algunas reglas del depósito, es superior a la que plantean algunos códigos en orden a que ese depósito es un mutuo o se rige por las reglas del mutuo.

6) Todavía la ley conoce otras figuras que es posible reconducir al esquema del crédito. Tal acontece en materia de sociedad conyugal con los bienes y deudas que forman su haber o, respectivamente, su pasivo relativos o aparentes.

15 Artículo 2216 inciso $2^{\circ}$ CC.: "El depositario, sin embargo, habiendo padecido error acerca de la persona del depositante, o descubriendo que la guarda de la cosa depositada le acarrea peligro, podrá restituir inmediatamente el depósito". 
El primer caso trata de bienes (dinero, fungibles, parte de un tesoro) que ingresan en el haber de la sociedad conyugal pero cuyo valor, al disolverse esta, debe ser restituido al cónyuge (o a sus herederos) por cuya vía el bien llegó al haber común. La restitución de valor toma el nombre de "recompensa". De ellas tratan los artículos 1725 números 3 y $4^{16}$ y $1731^{17}$.

El segundo caso atańe a deudas personales de cada cónyuge que la ley imputa, sin embargo, a la sociedad conyugal, por cuyo pago, en contrapartida, el respectivo cónyuge debe el reembolso a la sociedad (la ley habla de "compensar" a esta). Las trata el artículo $1740 \mathrm{~N}^{\circ} 3^{18}$.

Como puede percibirse, en ambos casos se trata de bienes que la sociedad adquiere en dominio, pero debe en valor al cónyuge; o de valores que este debe a la sociedad que pagó deudas suyas con subrogación legal. En ellos, pues, un valor ha quedado acreditado en favor del cónyuge o de la sociedad,

7) Todas las figuras que podemos reconducir al esquema que los antiguos juristas romanos denominaban dare ob rem, pertenecen también a la categoría que estudiamos. Traducimos aquella expresión por "dación por un fin", y consiste en que alguien dé algo a otro, o sea le transfiera el dominio de una cosa corporal o incorporal, en espera de que algo siga o acaezca o tenga lugar, de modo que si sigue el accipiente retenga lo recibido y si no sigue lo restituya al que lo había dado. En espera de que el fin siga, la cosa dada pertenece al que la recibió, porque hubo dación; pero la debe al que se la dio; vale decir se trata de una cosa acreditada. Téngase muy presente que no interviene en esta figura ninguna condición, como alguien podría pensarlo al interpretar como tal el fin futuro que se acuerda. No hay condición suspensiva porque la dación es actual e inmediata y no se suspende pues; ni resolutoria, porque haciendo defecto el fin la dación, esta no queda sin efecto, de modo de hacer posible la acción reivindicatoria para recuperarla, y sigue siendo necesaria una acción personal (la antigua condictio) para tal función.

16 Artículo 1725 CC.: "El haber de la sociedad conyugal se compone: [...] 3. Del dinero que cualquiera de los cónyuges aportare al matrimonio, o durante él adquiriere; obligándose la sociedad a pagar la correspondiente recompensa; 4 . De las cosas fungibles y especies muebles que cualquiera de los cónyuges aportare al matrimonio, o durante él adquiriere; quedando obligada la sociedad a pagar la correspondiente recompensa [...]".

17 Artículo 1731 CC.: "La parte del tesoro, que según la ley pertenece al que lo encuentra, se agregará al haber de la sociedad, la que deberá al cónyuge que lo encuentre la correspondiente recompensa; y la parte del tesoro, que según la ley pertenece al dueño del terreno en que se encuentra, se agregará al haber de la sociedad, la que deberá recompensa al cónyuge que fuere dueño del terreno".

18 Artículo $1740 \mathrm{~N}^{\circ} 3$ CC. "La sociedad es obligada al pago: "[...]/ 3. De las deudas personales de cada uno de los cónyuges, quedando el deudor obligado a compensar a la sociedad lo que ésta invierta en ello [...]". 
Supóngase que Ticio, deseoso de adquirir una pieza muy valiosa perteneciente a Cayo y que este se niega a vender, deposita una gran suma en la cuenta corriente de este, vale decir, se la da, y le escribe: "a cambio de la suma que te he depositado envíame la pieza a tal domicilio". Todos ven que esto no constituye una compraventa, porque falta el consenso de Cayo en orden a vender. Pero es claro que si este opta por remitir la pieza como le indicó Ticio, se ha perfeccionado una compraventa. Ahora bien, ¡cómo describir la figura previa, entre el depósito y el envío de la pieza a Ticio? Los juristas romanos no hubieran titubeado en decir que se trata de un dare ob honestam rem ut res sequatur; según ello, Ticio ha dado una cantidad de dinero para que Cayo le dé cierta pieza; el cual no está obligado a darla. Por cierto se hace dueño de la cantidad pero la debe; y si da a su vez la pieza ahora puede retener la cantidad y lucrarla definitivamente; si opta por no darla ciertamente debe restituir la cantidad recibida y Ticio puede cobrársela. Decimos, pues, que la cantidad quedó acreditada a Cayo y es como si Ticio se la hubiera dado en mutuo, lo cual solo constituye una comparación explicativa de la cual no debemos extraer otras consecuencias.

Ahora bien el antes descrito es un esquema negocial, que las partes pueden aplicar indefinidamente bajo el concepto de establecer el fin de quieran para dar, con tal que sea lícito. Si yo, por ejemplo, deseo contratar como doméstico el que lo sea der otro y doy a este algo para que acepte liberar a su empleado, eso es un dare ob rem; si el beneficiado acepta liberarlo, puede retener lo que le di; si no lo acepta, debe devolvérmelo.

Pero el Código conoce algunas aplicaciones típicas del dare ob rem, aunque no las trata bajo ese concepto. Me limitaré a señalar dos ejemplos.

El primero es la datio propter mortis causa donationem, o sea la dación de cosas merced a una donación por causa de muerte (o revocable). Alguien da una cosa a otro, actuando movido por la idea abstracta de que ha de morir (cogitatio mortalitatis) o concreta de estar amenazado cercanamente de muerte, como por una enfermedad letal. Con la dación, el donatario adquiere actualmente solo el usufructo de la cosa (artículo 1140 CC.), que sus herederos deben restituir al donante si aquel premuere (artículo 1143 CC.); y que se confirma como legado (artículo 1141 inciso $1^{\circ}$ CC.), si el donante premuere al donatario, quien, por ende, ahora adquiere el dominio (artículo 1144 CC.). He explicado el caso según los parámetros del derecho chileno, que a la donación por causa de muerte o revocable confiere un régimen muy especial en el $\$ 7$ del título $4^{\circ}$ del libro III CC.

El segundo ejemplo es la dación de arras (datio arrarum), o entrega de una cosa en prenda de la celebración o ejecución de un contrato de compraventa aun no convenido. En tal caso, el artículo 1803 CC. dice que cada parte puede retractarse de celebrar el contrato, perdiendo las arras el que las dio y restituyéndolas dobladas el que las recibió. Ahora 
bien, si las partes celebran el contrato hasta ese momento meramente proyectado, aunque la ley nada diga es claro que no las pierde el que dio arras y que quien las recibió debe restituirlas in simplum. La constitución de arras, por ende, es una datio ob rem: se las da para que se celebra un contrato aun no perfecto; perfeccionado el cual deben ser devueltas.

8) Podríamos seguir esta tarea interesante de localizar figuras tipificadas por la ley, que pueden ser entendidas bajo la idea general de crédito o especial de datio ob rem. Con lo dicho, empero, es suficiente. Y termino declarando que para mí ha sido un recurso inestimable haber recurrido tal idea, prácticamente abandonada en la moderna doctrina, y redescubrirla como categoría dogmática del derecho positivo para explicar los actos irregulares, cuya amplia investigación en el derecho chileno estoy por terminar. Pero debo reconocer que nada de ello me hubiera sido posible sin el presupuesto del dato romanístico ${ }^{19}$, que una vez más demuestra su poderosa virtud y presencia.

\section{BIBLIOGRAFÍA}

- D'Ors, Álvaro (1953), “Observaciones sobre el "edictum de rebus creditis". Studia et Documenta Historiae et Iuris, No 19.

- D'Ors, Álvaro (1956), "Creditum" y “contractum". Anuario de Historia del Derecho Español, vol. 26.

- D'Ors, Álvaro (1963), “Creditum”. Anuario de Historia del Derecho Español, vol. 33.

- D'Ors, Álvaro (1975), "Réplicas panormitanas, I: De nuevo sobre "creditum" (Réplica a la crítica de Albanese)". Studia et Documenta Historiae et Iuris, No 41.

- D'Ors, Álvaro (1991), Derecho privado romano, Pamplona, Eunsa, $8^{\text {a }}$ edición.

- García-Hervás, Dolores (1989), “Teoría del “creditum”. Cuadernos informativos de derecho histórico público, procesal y de la navegación, Nros. 9-10.

19 La noción de creditum fue rescatada por el gran romanista español Álvaro d'Ors (19152004) a través de numerosos escritos, de los cuales los principales son los signados bajo su nombre con los años 1953, 1956, 1963, 1975 y 1991 de la "Bibliografía". Las doctrinas d'Ors sobre la materia han sido sistematizadas por García-Hervás, Dolores (1989), "Teoría del "creditum". Cuadernos informativos de derecho histórico público, procesal y de la navegación, Nros. 9-10, pp. 1.887-2.038. He expuesto mi propia versión del creditum romano en Guzmán Brito, Alejandro (2006), "Dare ob rem", en Terrazas Ponce, Juan David (editor): Caminos romanos. Viae Romanae. Estudios en homenaje a Francisco Samper Polo, Santiago de Chile, Universidad Andrés Bello, pp. 149-192. 
- Guzmán Brito, Alejandro (2006), "Dare ob rem”, en Terrazas Ponce, Juan David (editor): Caminos romanos. Viae Romanae. Estudios en homenaje a Francisco Samper Polo, Santiago de Chile, Universidad Andrés Bello.

- Guzmán Brito, Alejandro (2006), "La tipología de los legados en el Derecho civil chileno". Revista de Derecho de la Pontificia Universidad Católica de Valparaíso, vol. 27, No 2

- Guzmán Brito, Alejandro (2007), "El justo título traslaticio de dominio de la tradición en el pago y en las operaciones crediticias, en Corral Talciani, Hernán y Rodríguez Pinto, María Sara (coordinadores), Estudios de Derecho Civil II: Jornadas Nacionales de Derecho Civil. Santiago: LexisNexis

- Guzmán Brito, Alejandro (2007 a), "La consensualización de los contratos reales", en Revista de Derecho de la Pontificia Universidad Católica de Valparaiso, 29/2 = Homenaje a Fernando de Trazegnies Granda, Lima, Fondo Editorial de la Pontificia Universidad Católica del Perú, 2009, II.

- Simonetto, Ernesto (1953/1958), Los contratos de crédito, traducción al castellano, Madrid, Bosch. 